\title{
ESTRUTURA DE OCUPAÇÕES E DISTRIBUIÇÃO DE RENDIMENTOS: UMA ANÁLISE DA EXPERIÊNCIA BRASILEIRA NOS ANOS 2000*
}

\begin{abstract}
Alexandre Gori Maia ${ }^{a}$
RESUMO: Em um contexto de profundas transformações na economia e no mercado de trabalho, o objetivo deste trabalho é analisar as relações entre a dinâmica da estrutura de ocupações e da distribuição de rendimentos no Brasil nos anos 2000. Primeiramente, verifica-se em que medida a prevalência de ocupações pouco qualificadas e de baixa remuneração contribui para o elevado estágio de exclusão e desigualdade do país. Verifica-se ainda como as mudanças na composição e nos rendimentos dos principais grupos ocupacionais contribuíram para o crescimento da renda e a redução da desigualdade no Brasil. Os resultados destacam a importância da estrutura ocupacional para compreensão das extremas diferenças socioeconômicas existentes no país.
\end{abstract}

PALAVRAS-CHAVE: Estrutura ocupacional; ocupações; mercado de trabalho; desigualdade.

CLASSIFICAÇÃO JEL: J21; J82; D31.

a Doutor em Economia Aplicada pela Universidade Estadual de Campinas (Unicamp), pós-doutor em Estudos Latino-Americanos pela Universidade do Texas e em Geografia pela Universidade de São Paulo (USP), professor do Instituto de Economia da Unicamp. Contato: gori@eco.unicamp.br. 


\title{
OCCUPATIONAL STRUCTURE AND INCOME DISTRIBUTION: AN ANALYSIS OF THE BRAZILIAN EXPERIENCE IN THE 2000S
}

\begin{abstract}
Considering the huge changes witnessed in the economy and in the labor market in Brazil in the 2000s, this paper analyzes the relationship between the occupational structure and the income distribution in this country. First, the paper analyzes in what extent the predominance of low-wage, unskilled occupations contributes to the high level of socioeconomic exclusion and inequality in Brazil. Analyses also consider how changes in the composition and in the average income of the main occupational groups have contributed to increase total income and reduce inequality in Brazil. In general, results show the importance of the occupational structure as an instrument to analyze socioeconomic differences in Brazil.
\end{abstract}

KEYWORDS: Occupational structure; occupations; labor market; inequality. 


\section{INTRODUÇÃO}

Este artigo analisa as relações entre a estrutura de ocupações e a distribuição de rendimentos no Brasil. O pressuposto das análises é que a estrutura ocupacional brasileira, caracterizada pela prevalência de ocupações pouco qualificadas e de baixa remuneração, seria um determinante fundamental do elevado estágio de exclusão e desigualdade socioeconômica do país. Ademais, o desenvolvimento da estrutura ocupacional nos anos 2000, período marcado por extremo dinamismo da atividade econômica, seria um importante dinamizador da redução da desigualdade. Para cumprir com os objetivos propostos, analisa-se em que medida a mudança na composição dos principais grupos ocupacionais, assim como as variações observadas em seus rendimentos médios, afetaram o crescimento da renda e a redução da desigualdade da população ocupada.

Nos anos 2000 o Brasil passou por contextos econômicos bastante favoráveis. Após décadas de baixo crescimento, o Produto Interno Bruto (PIB) real cresceu a uma taxa anual de 3,9\% entre 2002 e 2011 (IPEADATA, 2013), impulsionado pela valorização do preço das commodities no mercado internacional e pelo crescente superávit primário (CEPAL, 2007). No mercado de trabalho, resultados positivos foram observados com o crescimento da renda média real, redução da desigualdade, queda do grau de informalidade e da taxa de desemprego, assim como a absorção de mão de obra mais qualificada (Corseuil et al., 2011).

Este trabalho busca responder algumas importantes questões associadas à dinâmica do mercado de trabalho nos anos 2000. Em primeiro lugar, qual a contribuição da estrutura de ocupações para o estágio de desenvolvimento do mercado de trabalho e da desigualdade no Brasil? Ademais, haveriam ocorrido mudanças na estrutura ocupacional, por exemplo, maior participação de ocupações mais qualificadas, que justifiquem o crescimento dos rendimentos e a queda da desigualdade? Seriam as ocupações mais qualificadas, associadas ao mercado mais estruturado, as mais beneficiadas nessa dinâmica? E, finalmente, pode-se afirmar que a redução da desigualdade esteja associada à redução das ocupações menos qualificadas, caminhando o Brasil para uma estrutura mais equitativa?

Analisar a relação entre a estrutura de ocupações e a distribuição de rendimentos traria novos e importantes elementos para compreender o quadro de desigualdade socioeconômica no Brasil. Além de definir a probabilidade presente de geração de renda dos indivíduos, as ocupações cumpririam um papel fundamental na definição das relações sociais e das oportunidades econômicas nas sociedades modernas. Como fontes de renda, as ocupações estariam associadas às expectativas de vida dos indivíduos, contribuindo para explicar as desigualdades em uma economia de mercado (Rose e 
Harrison, 2007). Como normalmente acarretam certa dose de prestígio, seriam também relevantes para o status social do indivíduo (Quadros e Maia, 2010). Implicariam ainda determinados níveis de poder na sociedade, seja diretamente sobre os subordinados de uma empresa, ou indiretamente em outras áreas da vida social (Mills, 1979). Ademais, mudanças na estrutura ocupacional estariam associadas a mudanças na demanda por diferentes tipos de produtos e serviços, resultados de progressos socioeconômicos e tecnológicos, pelos quais passa a sociedade (Blau e Duncan, 1967).

As análises deste artigo serão apresentadas em três itens, além desta parte introdutória e das considerações finais. Primeiramente, apresenta-se uma breve descrição da dinâmica da desigualdade e do mercado de trabalho no Brasil, assim como seus principais determinantes estruturais. Posteriormente, apresentam-se os métodos para análise da dinâmica da distribuição de rendimentos, destacando os indicadores para decomposição da variação no rendimento médio e na desigualdade. No terceiro item, apresentam-se os resultados para a composição e dinâmica da estrutura ocupacional brasileira, assim como seus impactos na distribuição de rendimentos.

\section{MERCADO DE TRABALHO E DESIGUALDADE NO BRASIL}

Alguns fatores são fundamentais para compreender o extremo grau de exclusão e desigualdade no Brasil. Primeiro, deve-se considerar o processo histórico de desenvolvimento socioeconômico do país. Furtado (1986), por exemplo, destaca a extrema concentração de terras em favor de um restrito número de proprietários, observada desde a colonização do país. A herança deixada pela sociedade escravista teria ainda repercutido na forma de exclusão social de uma parcela expressiva da população.

A dinâmica do mercado de trabalho também contribuiu para reproduzir os elevados níveis de pobreza e desigualdade. Os diversos ciclos de crescimento econômico pelos quais passou o país não foram suficientes para absorver integralmente o excedente de mão de obra, reduzindo a pressão por aumento dos salários ao mesmo tempo em que se observavam relevantes ganhos de produtividade em setores-chave da economia (Oliveira e Henrique, 1990). Fishlow (1972) e Hoffmann e Duarte (1972) sugeriram ainda que o rápido crescimento da desigualdade nos anos 1960 e 1970 estaria associado à política de compressão salarial implantada no governo militar, que teria favorecido a desvinculação entre salários e crescimento do excedente nos setores mais dinâmicos da economia.

O mercado de trabalho brasileiro apresenta ainda duas características que merecem destaque nessas análises: (i) a estrutura produtiva pouco desenvolvida; e (ii) a baixa qualificação da mão de obra. O padrão primário-exportador, caracterizado pela produção e exportação de produtos primários aos centros industriais foi, por muito tempo, 
apontado como determinante fundamental da pobreza das massas latino-americanas (Prebisch, 2008). A industrialização, que garantiria a reestruturação da economia e da sociedade, teria se especializado em bens duráveis de alto valor unitário em países de baixo nível de renda per capita. Além de baixa incorporação de mão de obra, a dinâmica reproduzia a elevada desigualdade na distribuição de rendimentos.

A baixa qualificação da mão de obra no país contribui ainda para limitar os ganhos de produtividade que, por sua vez, é um determinante fundamental da renda e da qualidade do emprego (OIT, 2005). Menezes-Filho (2001), por exemplo, sugere que a falta de sintonia entre a oferta de empregos e a disponibilidade de mão de obra qualificada teria contribuído para aumentar as taxas de desemprego e informalidade dos grupos de qualificação intermediária do país nos anos 1990. A qualificação da mão de obra teria ainda influenciado decisivamente a distribuição de rendimentos. Langoni (1973), por exemplo, atribuiu o crescimento da desigualdade nos anos 1970 à interação entre o rápido crescimento econômico e a baixa disponibilidade de mão de obra qualificada, que proporcionou melhores oportunidades e remunerações a uma pequena parcela de profissionais mais qualificados. Por sua vez, Ferreira et al. (2006) sugeriram que o crescimento da escolaridade da mão de obra nos anos 1980 e 1990 teria agido de duas formas sobre a dinâmica da desigualdade: (i) aumentando a desigualdade no anos 1980, pelo fato de o efeito negativo da nova composição dos grupos educacionais sobrepor-se ao impacto positivo do declínio dos retornos marginais da educação sobre a remuneração; e (ii) reduzindo a desigualdade nos anos 1990, pela redução dos retornos marginais da educação.

Além de intensos esforços para qualificação da mão de obra, o crescimento econômico seria uma condição essencial para melhorar a quantidade e qualidade do emprego no país, garantindo ganhos de produtividade e aumento reais dos salários (Hull, 2009). Para que gere os efeitos desejados, o crescimento econômico deveria ainda ser acompanhado de políticas que promovam, por exemplo, o crescimento do emprego nos setores mais produtivos, o aumento da produtividade nos setores menos produtivos e a redução das barreiras para acesso dos trabalhadores às melhores posições do mercado de trabalho. O problema é que, após quase 50 anos de intenso crescimento econômico, a economia brasileira mergulhou em uma dura estagnação econômica nas décadas de 1980 e 1990. Nesse período, observou-se uma preocupante redução do número de pessoas com empregos em estabelecimentos minimamente estruturados, ao mesmo tempo em que cresceu expressivamente a participação da população em idade ativa e aquela à procura pelo emprego (Baltar, 1998).

Maia e Quadros (2010), analisando a dinâmica das ocupações nesse período, descrevem um processo de regressão de alguns dos principais indicadores da quantidade e 
qualidade do emprego, como o predomínio da geração de ocupações pouco qualificadas e a aproximação dos padrões de remuneração das ocupações melhor qualificadas em relação àquelas da base da pirâmide ocupacional. A manutenção de expressivas diferenças entre os rendimentos das ocupações, assim como das características socioeconômicas que definem os seus ocupados, seria um importante componente da desigualdade no mercado de trabalho e da concentração da pobreza no país.

Nos anos 2000, entretanto, a economia brasileira passou por contextos econômicos mais favoráveis, com impactos positivos no crescimento da renda, redução do desemprego e da desigualdade (Corseuil et al., 2011). Diversas mudanças também ocorreram na estrutura do mercado de trabalho e no perfil dos trabalhadores nessa década. Por exemplo, a mecanização agrícola vem gradativamente substituindo o trabalhador braçal pelo operador de máquinas e reduzindo o emprego agrícola (Gasques et al., 2010). Sobretudo nas áreas de maior dinamismo econômico, tem aumentado a demanda de mão de obra mais qualificada e mais especializada em detrimento do trabalho manual não qualificado que, em grande medida, tem sido o estereótipo do trabalhador brasileiro (Buainain e Dedecca, 2008). Um dos reflexos dessa dinâmica foi a redução da participação do trabalhador não remunerado e o crescimento do emprego com carteira. A escolaridade também tem aumentado nas atividades agrícolas e não agrícolas, assim como tem reduzido as diferenças entre os rendimentos de ocupados com distintos graus de escolaridade (Hoffmann e Ney, 2008). Ademais, as quase que contínuas valorizações reais do salário mínimo têm causado profundas transformações na estrutura de rendimentos dos ocupados, com impactos mais expressivos sobre os trabalhadores formais com rendimentos mais baixos (Saboia, 2010).

Este estudo pretende dar continuidade ao importante debate sobre a dinâmica do mercado de trabalho no Brasil, analisando sua relação com a distribuição de rendimentos. Especificamente, pretende-se verificar a associação entre a estrutura de ocupações e a distribuição de rendimentos no país, assim como os impactos das mudanças observadas na composição e nos rendimentos dos grupos ocupacionais sobre a desigualdade nos anos 2000.

\section{MATERIAL E MÉTODOS}

\subsection{ESTRUTURA DE OCUPAÇÕES}

A dinâmica das ocupações nos anos 2000 foi analisada a partir de informações da base de microdados da Pesquisa Nacional por Amostra de Domicílios (PNAD) do Instituto Brasileiro de Geografia e Estatística (IBGE). A partir da PNAD de 2002, o IBGE adotou uma nova classificação de ocupações (Classificação Brasileira de Ocupações/CBO, 
de 2000), permitindo, entre outras coisas, o uso integrado de suas informações com as provenientes de outras fontes de dados oficiais.

Dois níveis hierárquicos foram considerados nas análises: (i) ocupações; e (ii) grupos ocupacionais. O primeiro considera aproximadamente 490 ocupações identificadas pela nova $\mathrm{CBO}^{1}$, sendo o maior nível de desagregação das ocupações disponibilizado pelo IBGE. O segundo considera a agregação dessas ocupações em oito grupos ocupacionais, com o objetivo de sintetizar a apresentação e análise dos resultados. A composição desses grupos é apresentada na Tabela 1 .

Tabela 1 - Descrição dos grupos ocupacionais e códigos correspondentes na CBO 2000

\begin{tabular}{|c|c|c|}
\hline Grupo ocupacional & Descrição & CBO 2000 \\
\hline $\begin{array}{l}\text { Executivos, } \\
\text { administradores } \\
\text { e gerentes }\end{array}$ & $\begin{array}{l}\text { Executivos, dirigentes, administradores e } \\
\text { ocupações gerenciais (excluindo agrícolas) }\end{array}$ & $1111-1320 ; 4101-4102$ \\
\hline $\begin{array}{l}\text { Profissionais } \\
\text { e técnicos }\end{array}$ & $\begin{array}{l}\text { Profissionais especialistas, técnicos e outras } \\
\text { ocupações relacionadas }\end{array}$ & $\begin{array}{l}2011-2516 ; 2611-3132 ; 3137-3411 ; 3421-3422 ; 3425- \\
3426 ; 3531-3532 ; 3547 ; 3711-3722 ; 3732-3773\end{array}$ \\
\hline $\begin{array}{l}\text { Suporte } \\
\text { administrativo }\end{array}$ & $\begin{array}{l}\text { Suporte administrativo e outras ocupações } \\
\text { relacionadas }\end{array}$ & $\begin{array}{l}4110-4152 ; 2521-2525 ; 3511-3515 ; 3523-3525 ; 3542 ; \\
3723 ; 3731 ; 4201 ; 4212 ; 4214 ; 4221-4223 ; 4231 ; 4241\end{array}$ \\
\hline Vendas & Ocupações de vendas & $\begin{array}{l}2531 ; 3517 ; 3541 ; 3543 ; 3544 ; 3545 ; 3546 ; 3548 ; 4211 ; \\
5201-5243\end{array}$ \\
\hline Serviços & $\begin{array}{l}\text { Ocupações de serviços e segurança privada } \\
\text { (excluindo serviço doméstico) }\end{array}$ & $\begin{array}{l}401-513 ; 4213 ; 3518 ; 3522 ; 5101-5111 ; 5114-5134 ; \\
5151-5191 ; 5198-5199\end{array}$ \\
\hline $\begin{array}{l}\text { Trabalhadores } \\
\text { manuais }\end{array}$ & $\begin{array}{l}\text { Operadores, trabalhadores da indústria, } \\
\text { manutenção e operação, entre outras } \\
\text { ocupações manuais de baixa qualificação }\end{array}$ & $\begin{array}{l}\text { 3134-3136; 3412-3413; 3423-3424; 3516; 3911-3912; } \\
5112 ; 5141 ; 5142 ; 5192 ; 7101-9922\end{array}$ \\
\hline Emprego doméstico & Serviço doméstico remunerado & Posição na ocupação = 2 \\
\hline Agrícola & $\begin{array}{l}\text { Ocupações do ramo da agricultura, } \\
\text { pecuária, silvicultura e pesca. }\end{array}$ & $6110-6430$ \\
\hline
\end{tabular}

Fonte: Elaboração própria.

O critério de agregação deste trabalho buscou privilegiar a conformação de grupos relativamente homogêneos no que se refere ao poder e status socioeconômico das ocupações (Quadros e Maia, 2010; Portes e Hoffmann, 2003). Executivos, administradores e gerentes estariam em uma posição superior na estrutura de ocupações, pois, tendo ou não propriedade direta do capital controlariam pequenas, médias e grandes corporações e seus empregados. Profissionais e técnicos são ocupados mais qualificados, muitos com diploma universitário, empregados em instituições públicas e privadas para assumir

1 Foram identificadas 488 ocupações na PNAD de 2002 e 496 na PNAD de 2011. 
posições de maior prestígio e responsabilidade. Ocupações do suporte administrativo representam os assalariados de escritório, posições também características da classe dos colarinhos brancos (Mills, 1979). O grupo dos ocupados em vendas considera o crescente número de trabalhadores em pequenos ou grandes estabelecimentos comerciais, um grupo heterogêneo de ocupados com status socioeconômico muitas vezes associado ao de seus clientes. Trabalhadores manuais e ocupados nos serviços representam ocupados pouco qualificados, que se diferenciam mais pela atividade que desempenham do que pela posição socioeconômica apresentada. Na base da pirâmide, encontram-se os trabalhadores domésticos e agrícolas, ocupados em posições que exigem baixa qualificação e usualmente vinculados à economia informal.

Por ser um critério qualitativo de estratificação, a hierarquização proposta não representa uma escala medindo as diferenças entre os grupos ocupacionais, mas sim uma aproximação dos padrões socioeconômicos determinados pela inserção dos ocupados no mercado de trabalho. Em outras palavras, embora alguns grupos estejam subordinados a outros, não é possível quantificar essa relação.

Ademais, não se podem desconsiderar significativas distinções socioeconômicas que surgem dentro de cada um desses agrupamentos ocupacionais. Esta desigualdade é ainda mais acentuada pelo fato de se tratar de uma sociedade notadamente heterogênea como a brasileira, na qual, mesmo em grupos sociais com oportunidades relativamente homogêneas, é comum encontrar significativas distorções distributivas (Maia, 2009). Para considerar essa heterogeneidade, as análises deste trabalho destacam tanto as diferenças entre os grupos ocupacionais como as diferenças entre as ocupações de um mesmo grupo ocupacional.

Foram considerados como ocupadas aquelas pessoas com dez anos ou mais de idade que apresentavam alguma atividade remunerada na semana de referência. Ocupados não remunerados, incluindo aqueles em atividades para o autoconsumo e na construção para o uso próprio, foram desconsiderados por duas razões principais: (i) destacar as mudanças percebidas no mercado de trabalho mais estruturado do país; e (ii) evitar distorções e viabilizar metodologicamente a decomposição da dinâmica da desigualdade, como será descrito nos próximos tópicos.

Os rendimentos da ocupação principal foram deflacionados para reais ( $\mathrm{R} \$$ ) de outubro de 2011 a partir do INPC corrigido para a PNAD; um ajuste feito no índice de inflação para que esse considere as variações percebidas no dia primeiro de cada mês, período de referência para os rendimentos captados pela $\mathrm{PNAD}$, e não permaneça centrado no dia 15 de cada mês como originalmente prevê sua metodologia (Corseuil e Foguel, 2002). 


\subsection{DECOMPOSIÇÃO DA VARIAÇÃO NO RENDIMENTO MÉDIO}

A dinâmica do rendimento médio foi decomposta para considerar três componentes: (i) mudanças na composição dos grupos ocupacionais (efeito composição dos grupos); (ii) mudanças na composição das ocupações dentro dos grupos ocupacionais (efeito composição das ocupações); e (iii) mudanças nos valores dos rendimentos médios dentro das ocupações (efeito renda).

Primeiro, seja $\Delta \bar{Y}$ a variação total no rendimento médio da população ocupada entre os períodos $t-1$ e $t$. Essa variação pode ser representada pela soma ponderada das variações dos rendimentos médios nos grupos ocupacionais:

$$
\Delta \bar{Y}=\sum_{g=1}^{G} \Delta\left(p_{g} \bar{Y}_{g}\right)
$$

Onde $p_{g}$ é a proporção de ocupados no grupo ocupacional $g$ e $\bar{Y}_{g}$ o rendimento médio desse grupo. Através de desenvolvimento algébrico, pode-se chegar à seguinte igualdade:

$$
\Delta \bar{Y}=\sum_{g=1}^{G}\left[\Delta p_{g}\left(\overline{\bar{Y}}_{g}-\overline{\bar{Y}}\right)+\bar{p}_{g} \Delta \bar{Y}_{g}\right]
$$

Onde $p_{g}$ é a proporção de ocupados no grupo ocupacional $g, \bar{p}_{g}$ a respectiva proporção média nos períodos $t-1$ e $t, \bar{Y}_{g}$ é a renda média desse grupo, $\overline{\bar{Y}}_{g}$ o respectivo valor médio nos períodos $t-1$ e $t$ e $\overline{\bar{Y}}$ a renda média de toda a população ocupada nos mesmos períodos. O primeiro termo da expressão (2) representa o efeito composição do grupo ocupacional $g$, ou seja, a parcela da variação do rendimento médio devida à mudança na participação relativa deste grupo ocupacional. Por sua vez, o segundo termo representa o efeito renda do grupo e expressa a parcela da variação devida à variação na renda média deste grupo.

Considerando agora que cada grupo ocupacional $g$ seja composto por $C_{g}$ ocupações, a variação no rendimento médio poderá também ser expressa por:

$$
\Delta \bar{Y}=\sum_{g=1}^{G} \sum_{c=1}^{C_{g}} \Delta\left(p_{g c} \bar{Y}_{g c}\right)
$$

Onde $p_{g c}$ é a proporção de ocupados do grupo ocupacional $g$ na ocupação $c$ e $\bar{Y}_{g c}$ o rendimento médio desta ocupação.

Combinando as expressões (2) e (3), a variação do rendimento médio seria também representada pela soma de três componentes:

$$
\Delta \bar{Y}=\sum_{g=1}^{G}\left[\Delta p_{g}\left(\overline{\bar{Y}}_{g}-\overline{\bar{Y}}\right)+\bar{p}_{g} \sum_{c=1}^{C_{g}} \Delta p_{g c}\left(\overline{\bar{Y}}_{g c}-\overline{\bar{Y}}_{g}\right)+\bar{p}_{g} \sum_{c=1}^{C_{g}} \bar{p}_{g c} \Delta \bar{Y}_{g c}\right]
$$


Ou resumidamente:

$$
\Delta \bar{Y}=\sum_{g=1}^{G}\left[E C G_{g}+E C O_{g}+E R_{g}\right]
$$

Onde $\bar{p}_{g c}$ é a proporção média de ocupados do grupo ocupacional $g$ na ocupação $c$, nos períodos $t-1$ e $t, \bar{Y}_{g c}$ é a renda média na ocupação $c$ e grupo $g$ e $\overline{\bar{Y}}_{g c}$ seu respectivo valor médio nos períodos $t-1$ e $t$. Assim, o termo $E C G_{g}$ representa o efeito composição de mudanças ocorridas na participação do grupo $g, E C O_{g}$ representa o efeito composição de mudanças ocorridas na participação das ocupações no interior do grupo $g$ e $E R_{g}$ representa o efeito renda de mudanças ocorridas no rendimento médio das ocupações do grupo ocupacional $g$.

\subsection{DECOMPOSIÇÃO DA VARIAÇÃO NA DESIGUALDADE}

A desigualdade entre e dentro dos grupos ocupacionais foi medida a partir do indicador $T$ de Theil. Seja $Y_{i}$ a renda do $i$-ésimo indivíduo e $Y$ a renda total de uma população de tamanho $n$. O cálculo do índice $T$ de Theil $(0 \leq T \leq \ln n)$ será dado por (Hoffmann, 1998):

$$
T=\sum_{i=1}^{n} \frac{Y_{i}}{Y} \ln n \frac{Y_{i}}{Y}
$$

A partir da propriedade de decomposição linear do $T$ de Theil, pode-se desagregar a desigualdade total em três componentes (Fishlow, 1972): (i) uma parcela devida às diferenças entre os grupos ocupacionais (TEG); (ii) uma parcela devida às diferenças entre as ocupações de um mesmo grupo ocupacional (TEO); e (iii) outra parcela devida à desigualdade interna às ocupações (TDO). Genericamente, tem-se que:

$$
T=T E G+T E O+T D O
$$

Sendo que:

$$
\begin{aligned}
& \text { TEG }=\sum_{g=1}^{G} \frac{Y_{g}}{Y} \ln \frac{Y_{g} / Y}{n_{g} / n}=\sum_{g=1}^{G} y_{g} \ln \frac{y_{g}}{p_{g}}=\sum_{g=1}^{G} y_{g} T E G_{g} \\
& T E O=\sum_{g=1}^{G} \frac{Y_{g}}{Y} \sum_{c=1}^{C_{g}} \frac{Y_{g c}}{Y_{g}} \ln \frac{Y_{g c} / Y_{g}}{n_{g c} / n_{g}}=\sum_{g=1}^{G} y_{g} \sum_{c=1}^{C_{g}} y_{g c} \ln \frac{y_{g c}}{p_{g c}}=\sum_{g=1}^{G} y_{g} T E O_{g} \\
& T D O=\sum_{g=1}^{G} \frac{Y_{g}}{Y} \sum_{c=1}^{C_{g}} \frac{Y_{g c}}{Y_{g}} T_{g c}=\sum_{g=1}^{G} y_{g} \sum_{c=1}^{C_{g}} y_{g c} T_{g c}=\sum_{g=1}^{G} y_{g} T D O_{g}
\end{aligned}
$$


Onde $Y_{g}$ é a soma dos valores de $Y_{i}$ para o grupo ocupacional $g, n_{g}$ é sua respectiva população, $Y_{g c}$ é a soma dos valores de $Y_{i}$ para a ocupação $c$ do grupo ocupacional $g$, e $n_{g c}$ é sua respectiva população. $T_{g c}$ representa a desigualdade interna à ocupação $c$ do grupo ocupacional $g$ e é obtido a partir da expressão (6) considerando apenas a população desse subconjunto ocupacional. Para simplificar as representações, as proporções de renda e população de cada subconjunto são representadas pelas variáveis $y$ e $p$, respectivamente.

A variação no indicador $T$ de desigualdade em um determinado período pode então ser decomposta em três componentes principais: (i) mudanças nas diferenças entre os grupos ocupacionais $(\triangle T E G)$; (ii) mudanças nas diferenças entre as ocupações de um mesmo grupo ocupacional ( $\triangle T E O)$; e (iii) mudanças na desigualdade interna às ocupações $(\triangle T D O)$.

$$
\Delta T=\Delta T E G+\triangle T E O+\Delta T D O
$$

Podemos ainda avaliar a contribuição de cada grupo ocupacional representando a variação do indicador $T$ de Theil como uma soma ponderada das variações ocorridas nos grupos:

$$
\Delta T=\sum_{g=1}^{G}\left[\Delta\left(y_{g} T E G_{g}\right)+\Delta\left(y_{g} T E O_{g}\right)+\Delta\left(y_{g} T D O_{g}\right)\right]
$$

O primeiro termo $\Delta\left(y_{g} T E G_{g}\right)$, ou efeito entre grupos, representa o efeito da variação da renda média relativa do grupo $g$, o segundo termo $\Delta\left(y_{g} T E O_{g}\right)$, ou efeito entre ocupações, representa o efeito da variação na desigualdade dos rendimentos entre as ocupações no interior do grupo $g$ e o último termo, $\Delta\left(y_{g} T D O_{g}\right)$, ou efeito dentro das ocupações, representa o efeito de mudanças ocorridas na desigualdade dos rendimentos dos ocupados de uma mesma ocupação do grupo ocupacional $g$.

\section{RESULTADOS}

\subsection{DINÂMICA DO EMPREGO E RENDA}

A estrutura ocupacional brasileira destaca, primeiro, a hierarquia dos grupos ocupacionais sob a forma de domínio dos rendimentos médios (Tabela 2). No topo da pirâmide ocupacional, com rendimentos médios superiores à média nacional, estariam os "colarinhos brancos": executivos, administradores, gerentes, profissionais, técnicos e, abaixo desses, os ocupados do suporte administrativo. Em seguida aparecem os ocupados em vendas, representando a massa heterogênea de vendedores, ocupados em grandes e médias unidades varejistas ou mesmo em pequenos estabelecimentos vinculados à economia informal. Trabalhadores manuais e ocupados nos serviços representam ex- 
pressivo número de trabalhadores pouco qualificados e de baixa remuneração. Na base da pirâmide, com rendimentos médios bem inferiores à média nacional, aparecem os trabalhadores domésticos e agrícolas.

Tabela 2 - Estrutura ocupacional dos ocupados remunerados (Brasil, 2002 e 2011)

\begin{tabular}{|c|c|c|c|c|c|c|c|}
\hline \multirow{2}{*}{\multicolumn{2}{|c|}{ Ocupação }} & \multicolumn{3}{|c|}{2002} & \multicolumn{3}{|c|}{2011} \\
\hline & & \multirow{2}{*}{$\begin{array}{c}\begin{array}{c}\text { Pessoas } \\
(1.000)\end{array} \\
2.163\end{array}$} & \multirow{2}{*}{$\begin{array}{c}\% \\
3,1\end{array}$} & \multirow{2}{*}{$\begin{array}{l}\text { Rnd. } \\
\text { Méd }\end{array}$} & \multirow{2}{*}{$\begin{array}{c}\begin{array}{c}\text { Pessoas } \\
(1.000)\end{array} \\
2.284\end{array}$} & \multirow{2}{*}{$\begin{array}{c}\% \\
2,7\end{array}$} & \multirow{2}{*}{$\begin{array}{l}\text { Rnd. } \\
\text { Méd }\end{array}$} \\
\hline & Gerentes de produção e operação & & & & & & \\
\hline & Gerentes de áreas de apoio & 736 & 1,1 & 3.057 & 746 & 0,9 & 3.447 \\
\hline 寻䒕 & Diretores de empresas (+ 5 empregados) & 623 & 0,9 & 5.537 & 619 & 0,7 & 6.143 \\
\hline $\begin{array}{lll}\pi & \tilde{D} \\
\hat{0} & 0 & 0\end{array}$ & Supervisores de serviços administrativos & 226 & 0,3 & 1.980 & 239 & 0,3 & 2.079 \\
\hline 恶 & Supervisores de serviços contábeis & 172 & 0,2 & 1.737 & 225 & 0,3 & 2.219 \\
\hline & Total & 4.380 & 6,3 & 3.232 & 4.572 & 5,4 & 3.489 \\
\hline \multirow{6}{*}{ 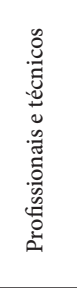 } & Técnicos e auxiliares de enfermagem & 455 & 0,7 & 1.132 & 820 & 1,0 & 1.210 \\
\hline & Professores 1a a 4a série fundamental & 256 & 0,4 & 1.184 & 682 & 0,8 & 1.440 \\
\hline & Professores de ensino médio & 310 & 0,4 & 1.736 & 624 & 0,7 & 1.890 \\
\hline & Advogados & 339 & 0,5 & 3.857 & 572 & 0,7 & 4.616 \\
\hline & Professores $5 \mathrm{a}$ a 8 a série fundamental & 421 & 0,6 & 1.402 & 475 & 0,6 & 1.630 \\
\hline & Total & 7.316 & 10,5 & 2.082 & 10.587 & 12,4 & 2.333 \\
\hline \multirow{6}{*}{ 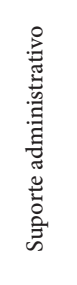 } & Escriturários e auxiliares administrativos & 1.615 & 2,3 & 1.081 & 3.055 & 3,6 & 1.250 \\
\hline & Recepcionistas & 630 & 0,9 & 708 & 1.073 & 1,3 & 797 \\
\hline & Secretárias de expediente e estenógrafos & 600 & 0,9 & 923 & 710 & 0,8 & 1.170 \\
\hline & Almoxarifes e armazenistas & 455 & 0,7 & 919 & 667 & 0,8 & 967 \\
\hline & Contadores e auditores & 221 & 0,3 & 3.886 & 410 & 0,5 & 4.160 \\
\hline & Total & 5.988 & 8,6 & 1.264 & 8.395 & 9,9 & 1.437 \\
\hline \multirow{6}{*}{$\frac{\stackrel{g}{\tilde{T}}}{\overrightarrow{0}}$} & Vendedores e demonstradores & 4.545 & 6,5 & 841 & 7.927 & 9,3 & 1.019 \\
\hline & Vendedores ambulantes & 1.672 & 2,4 & 503 & 1.123 & 1,3 & 735 \\
\hline & Representantes e técnicos de vendas & 819 & 1,2 & 1.901 & 718 & 0,8 & 1.959 \\
\hline & Vendedores a domicílio & 104 & 0,1 & 458 & 373 & 0,4 & 609 \\
\hline & Caixas e bilheteiros (exclusive banco) & 492 & 0,7 & 631 & 310 & 0,4 & 813 \\
\hline & Total & 8.500 & 12,2 & 927 & 11.635 & 13,7 & 1.109 \\
\hline \multirow{6}{*}{ 䓪 } & Garçons, barmen e copeiros & 1.318 & 1,9 & 715 & 1.856 & 2,2 & 842 \\
\hline & Cozinheiros & 960 & 1,4 & 552 & 1.511 & 1,8 & 718 \\
\hline & Serviços de higiene e embelezamento & 970 & 1,4 & 724 & 1.502 & 1,8 & 894 \\
\hline & Guardas e vigias & 1.025 & 1,5 & 700 & 1.027 & 1,2 & 834 \\
\hline & Outros trabalhadores dos serviços & 774 & 1,1 & 428 & 958 & 1,1 & 667 \\
\hline & Total & 7.558 & 10,9 & 776 & 9.860 & 11,6 & 978 \\
\hline
\end{tabular}




\begin{tabular}{|c|c|c|c|c|c|c|c|}
\hline \multirow{6}{*}{ 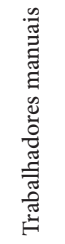 } & Estruturas de alvenaria & 1.681 & 2,4 & 749 & 2.836 & 3,3 & 1.068 \\
\hline & Ajudantes de obras civis & 1.357 & 2,0 & 421 & 2.191 & 2,6 & 622 \\
\hline & Manutenção e conservação de edifícios & 1.842 & 2,6 & 481 & 1.874 & 2,2 & 662 \\
\hline & Condutores de veículos (mercadorias) & 1.137 & 1,6 & 1.357 & 1.827 & 2,1 & 1.469 \\
\hline & Operadores de máquina de costura & 993 & 1,4 & 500 & 1.207 & 1,4 & 666 \\
\hline & Total & 20.789 & 29,9 & 792 & 25.458 & 29,9 & 1.036 \\
\hline 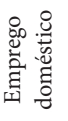 & & 6.072 & 8,7 & 360 & 6.576 & 7,7 & 505 \\
\hline \multirow{6}{*}{ 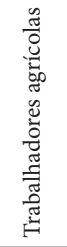 } & Produtores agrícolas & 3.253 & 4,7 & 606 & 2.359 & 2,8 & 755 \\
\hline & Trabalhadores agrícolas em geral & 1.906 & 2,7 & 346 & 2.259 & 2,7 & 534 \\
\hline & Trabalhadores na pecuária & 1.008 & 1,5 & 390 & 974 & 1,1 & 718 \\
\hline & Produtores em pecuária & 906 & 1,3 & 1.249 & 654 & 0,8 & 1.238 \\
\hline & Produtores em agropecuária em geral & 20 & 0,0 & 1.211 & 504 & 0,6 & 1.379 \\
\hline & Total & 8.926 & 12,8 & 550 & 7.992 & 9,4 & 759 \\
\hline Total & & 69.528 & 100,0 & 1.064 & 85.075 & 100,0 & 1.297 \\
\hline
\end{tabular}

Nota: Valores em $1^{\circ}$ de outubro de 2011 (INPC corrigido para PNAD - IPEA).

Fonte: Elaboração própria com base em microdados da PNAD/IBGE.

A hierarquia dos grupos ocupacionais também reflete, em grande medida, o nível de qualificação de seus ocupados. Uma maneira de analisar esse comportamento é a partir do grau de escolaridade dos ocupados. Por exemplo, as informações presentes no Apêndice A revelam que, entre os ocupados dos grupos mais qualificados (executivos, administradores, gerentes, profissionais, técnicos e trabalhadores do suporte administrativo), o percentual de pessoas com $3^{\circ}$ grau de escolaridade completo ou incompleto era superior a $42 \%$ em 2011, enquanto o percentual de ocupados com no máximo $1^{\circ}$ grau de escolaridade completo não era superior a 18\%. Entre os ocupados dos grupos menos qualificados (serviços, trabalhadores manuais, emprego doméstico e trabalhadores agrícolas), o percentual de pessoas com no máximo o $1^{\circ}$ grau completo era superior a $41 \%$ no mesmo período.

Outra característica da estrutura ocupacional brasileira é a elevada participação de ocupações de baixa qualificação e remuneração, que contribui em grande medida para o baixo rendimento médio da população ocupada. Por exemplo, em 2011, vendedores e trabalhadores domésticos eram as duas ocupações mais frequentes da estrutura ocupacional, representados por 14,5 milhões de ocupados (16\% do total de ocupados) com rendimentos médios de aproximadamente R $\$ 1.000$ e R \$ 500 mensais, respectivamente.

A heterogeneidade entre os grupos ocupacionais também é marcante. Há uma expressiva diferença entre os rendimentos das poucas ocupações mais qualificadas e os baixos rendimentos da grande massa de trabalhadores, o que ajuda a explicar o elevado grau de desigualdade dos rendimentos no mercado de trabalho brasileiro. Por exemplo, 
em 2011, o rendimento médio dos 25,5 milhões de trabalhadores manuais ( $\mathrm{R} \$ 1.036$ ) era 3,4 vezes inferior ao dos 4,6 milhões de executivos, administradores e gerentes (R\$ 3.489), e 2,3 vezes inferior ao dos 10,6 milhões de profissionais e técnicos ( $\mathrm{R} \$ 2.333$ ).

Houve, entretanto, mudanças positivas na estrutura ocupacional entre 2002 e 2011, com impactos significativos na composição das ocupações e na distribuição dos rendimentos. Destaque pode ser dado para a expressiva redução da participação da massa trabalhadora agrícola e crescimento da participação de ocupações melhor remuneradas, como profissionais, técnicos, ocupações de suporte administrativo e de vendas. Por exemplo, a mecanização agrícola e o êxodo rural contribuíram para reduzir em mais de 900 mil o número de ocupados agrícolas entre 2002 e 2011, redução de 3,4 pontos percentuais na participação da estrutura ocupacional. Por outro lado, o número de profissionais e técnicos cresceu em 3,3 milhões, o número de ocupados no suporte administrativo cresceu em 2,4 milhões e o número de ocupados em vendas cresceu em 3,1 milhões de pessoas.

O crescimento na participação de grupos ocupacionais de maior remuneração representou uma importante evolução da estrutura ocupacional. De maneira geral, pode-se dizer que houve um ligeiro estreitamento na base da pirâmide ocupacional e uma consequente maior representatividade dos grupos mais qualificados. Por exemplo, as mais frequentes ocupações dos grupos de profissionais, técnicos e auxiliares administrativos cresceram, predominantemente, em ritmo igual ou superior ao da média da população ocupada. No conjunto, a participação desses grupos aumentou em 1,9 pontos percentuais.

Nesse período, o número de ocupados aumentou em 15,5 milhões, com destaque para o crescimento de vendedores e demonstradores (aumento de 3,4 milhões de pessoas), escriturários e auxiliares administrativos (1,4 milhão de pessoas) e trabalhadores da construção civil (1,2 milhões de pedreiros de estruturas de alvenaria e 834 mil ajudantes de obras civis). A redução no número de produtores (a soma do número de produtores agrícolas, em pecuária e agropecuária em geral reduziu em 600 mil) e o crescimento no número de ocupados agrícolas classificados como trabalhadores agrícolas em geral (353 mil novas ocupações) indicam ainda importantes mudanças no perfil dos ocupados desse grupo, de perfil conta própria para o trabalho assalariado.

A dinâmica do rendimento médio das ocupações também revela resultados interessantes. No conjunto da população ocupada, a renda média cresceu R \$ 234 entre 2002 e 2011, o que equivale a uma variação real de 22\%. Embora o rendimento médio tenha crescido em todos os grupos ocupacionais e em praticamente todas as ocupações mais frequentes da estrutura ocupacional (exceção aos produtores em pecuária), o crescimento foi mais acelerado entre as ocupações dos grupos de renda mais baixa. Por exemplo, as variações dos rendimentos médios dos grupos de executivos, adminis- 
tradores e gerentes, profissionais e técnicos, e trabalhadores do suporte administrativo foram inferiores a $14 \%$. Por sua vez, as variações nos grupos dos ocupados em serviços, trabalhadores manuais, emprego doméstico e trabalhadores agrícolas foram superiores a $26 \%$, chegando a $40 \%$ entre os empregados domésticos.

Uma análise pormenorizada da dinâmica dos rendimentos dos grupos ocupacionais é apresentada na Tabela 3, dividindo os ocupados em quatro classes de rendimentos, com intervalos proporcionais ao valor do salário mínimo de 2011 ( $\mathrm{R}$ \$ 545): (A) R\$ 2.725 ou mais; (B) entre R\$ 1.090 e R\$2.725; (C) entre R\$ 545 e R\$ 1.090; (D) menos de R \$ 545. Primeiramente, destaca-se a expressiva participação de ocupados com rendimentos inferiores ao valor do salário mínimo de 2011 nos grupos na base da pirâmide ocupacional brasileira (classe D). Por exemplo, nos grupos de trabalhadores agrícolas e domésticos, mais de $60 \%$ dos ocupados recebiam rendimentos inferiores ao valor do salário mínimo em 2011, caracterizando a elevada informalidade a que seus ocupados estão sujeitos.

Tabela 3 - Distribuição dos ocupados remunerados segundo grupos ocupacionais e classes de rendimento (Brasil, 2002 e 2011)

\begin{tabular}{l|c|c|c|c|c|c|c|c}
\hline \multirow{2}{*}{ Grupo Ocupacional } & \multicolumn{4}{c|}{2002} & \multicolumn{4}{c}{2011} \\
\cline { 2 - 9 } & A & B & C & D & A & B & C & D \\
\hline Executivos, administradores e gerentes & 35,7 & 37,7 & 18,7 & 7,9 & 40,1 & 37,1 & 18,2 & 4,7 \\
\hline Profissionais e técnicos & 21,4 & 31,6 & 24,9 & 22,0 & 24,2 & 36,5 & 26,3 & 13,0 \\
\hline Suporte administrativo & 8,8 & 23,3 & 36,9 & 30,9 & 10,6 & 25,5 & 45,6 & 18,2 \\
\hline Vendas & 5,3 & 15,0 & 28,8 & 50,9 & 6,6 & 19,8 & 42,9 & 30,7 \\
\hline Serviços & 2,7 & 14,4 & 30,3 & 52,6 & 4,8 & 17,3 & 44,9 & 33,0 \\
\hline Trabalhadores manuais & 2,5 & 15,2 & 35,1 & 47,3 & 3,8 & 25,2 & 46,5 & 24,5 \\
\hline Empregos domésticos & 0,0 & 1,4 & 12,3 & 86,2 & 0,0 & 3,8 & 29,4 & 66,8 \\
\hline Trabalhadores agrícolas & 2,3 & 4,9 & 13,6 & 79,2 & 3,6 & 8,8 & 25,2 & 62,5 \\
\hline Total & 7,2 & 16,4 & 27,1 & 49,3 & 9,0 & 22,4 & 38,4 & 30,2 \\
\hline
\end{tabular}

Nota: Dados em \%.

Fonte: Elaboração própria com base em microdados da PNAD/IBGE.

Outro fato relevante foi a expressiva redução da participação de ocupados da classe D entre 2002 e 2011, provavelmente associada à redução da informalidade e à valorização do salário mínimo no período. Entretanto, a mobilidade concentrou-se nos grupos de renda intermediários: B e C. A variação na participação de ocupados na classe A foi expressiva apenas entre executivos, administradores e gerentes (4 pontos percentuais). Entre profissionais e técnicos, a participação cresceu mais na classe B ( 5 pontos percentuais). Nos demais grupos, a participação cresceu mais aceleradamente na classe C: entre 9 (suporte administrativo) e 17 pontos percentuais (trabalhadores manuais). Embora não haja elementos para desagregar o comportamento das novas inserções e das ocu- 
pações preexistentes, esses resultados sugerem o perfil das novas posições no mercado de trabalho: formal, mas de baixo rendimento, entre 1 e 2 salários mínimos (classe C).

Para finalizar essa descrição preliminar da estrutura ocupacional, a Tabela 4 apresenta a decomposição da dinâmica do rendimento médio em três fontes principais (equação 5): (i) mudanças na composição dos grupos ocupacionais (ECG); (ii) mudanças na composição das ocupações dentro dos grupos ocupacionais (ECO); e (iii) mudanças nos valores dos rendimentos médios dentro das ocupações (ER). O efeito composição dos grupos ocupacionais avalia, por exemplo, em que medida as reduções nas participações relativas de grupos de baixo rendimento médio afetaram positivamente a renda média dos ocupados. Analogamente, o efeito composição das ocupações avalia a contribuição das variações na participação das ocupações (de maior ou menor rendimento) dentro de cada grupo ocupacional. Por sua vez, o efeito renda verifica o impacto das variações nas rendas médias das ocupações sobre a renda média do total da população ocupada.

Da variação total na renda média dos ocupados entre 2002 e 2011 (R 234 ), 8 \% foram devidos ao ECG (R\$20), 4\% devidos ao ECO (R\$10) e 87\% devidos ao efeito das variações nos rendimentos médios ( $\mathrm{R}$ \$204). A maior contribuição ( $\mathrm{R}$ \$ 69, ou 30\%) foi dada pelo crescimento da renda média dos trabalhadores manuais, grupo mais expressivo da estrutura ocupacional brasileira. Os grupos de trabalhadores agrícolas e de profissionais e técnicos também tiveram papel importante no crescimento da renda média nacional, seja pelo efeito composição de variações em suas participações (redução do primeiro e aumento do segundo) ou pelo efeito renda da variação positiva de suas rendas médias. A renda média dos trabalhadores agrícolas cresceu 38\% entre 2002 e 2011, significando um crescimento de R\$ 21 no conjunto da população ocupada ( $9 \%$ da variação total). A renda média dos profissionais e técnicos, que cresceu $12 \%$ no período, significou uma variação de R 25 na renda total (11\%). Por sua vez, a maior participação de profissionais e técnicos (crescimento de 1,9 pontos percentuais) - grupo de renda média elevada - e a menor participação de trabalhadores agrícolas (redução de 3,4 pontos percentuais) - grupo de baixa renda média - também contribuíram significativamente para o crescimento da renda média total: $8 \%$ e 7,5\%, respectivamente. Variações na participação das ocupações desses grupos ocupacionais também contribuíram, em menor magnitude, para o crescimento da renda média total: $1,5 \%$ de contribuição das ocupações do grupo de profissionais e técnicos e 1,1\% do grupo de trabalhadores agrícolas. O grupo com impacto negativo mais expressivo sobre a dinâmica do rendimento médio foi o de executivos, devido à pequena redução de sua participação na estrutura ocupacional (redução de 0,9 pontos percentual), que significou uma redução de $8,9 \%$ da renda média dos ocupados em função de seu rendimento médio relativamente elevado. 
Tabela 4 - Decomposição da variação no rendimento médio dos ocupados remunerados (Brasil, 2002 e 2011)

\begin{tabular}{l|c|c|c|c|c|c|c|c}
\hline \multirow{2}{*}{ Grupo Ocupacional } & \multicolumn{4}{|c|}{ Variação Absoluta (R\$) } & \multicolumn{4}{c}{ Variação Relativa (\%) } \\
\cline { 2 - 10 } & ECG & ECO & ER & Total & ECG & ECO & ER & Total \\
\hline $\begin{array}{l}\text { Executivos, administradores } \\
\text { e gerentes }\end{array}$ & $-20,9$ & $-1,0$ & 15,7 & $-6,2$ & $-8,9$ & $-0,4$ & 6,7 & $-2,6$ \\
\hline Profissionais e técnicos & 18,7 & 3,6 & 24,8 & 47,1 & 8,0 & 1,5 & 10,6 & 20,2 \\
\hline Suporte administrativo & 2,0 & $-1,1$ & 17,1 & 17,9 & 0,8 & $-0,5$ & 7,3 & 7,7 \\
\hline Vendas & $-2,3$ & 1,7 & 21,8 & 21,2 & $-1,0$ & 0,7 & 9,3 & 9,1 \\
\hline Serviços & $-2,2$ & $-0,3$ & 23,0 & 20,5 & $-0,9$ & $-0,1$ & 9,9 & 8,8 \\
\hline Trabalhadores manuais & $-0,4$ & 4,4 & 69,1 & 73,2 & $-0,2$ & 1,9 & 29,6 & 31,3 \\
\hline Empregos domésticos & 7,0 & 0,1 & 12,0 & 19,2 & 3,0 & 0,0 & 5,1 & 8,2 \\
\hline Trabalhadores agrícolas & 17,6 & 2,6 & 20,6 & 40,8 & 7,5 & 1,1 & 8,8 & 17,5 \\
\hline Total & 19,6 & 10,0 & 204,1 & 233,7 & 8,4 & 4,3 & 87,3 & 100,0 \\
\hline
\end{tabular}

Nota: Valores em $1^{\circ}$ de outubro de 2011 (INPC corrigido para PNAD - IPEA). Fonte: Elaboração própria com base em microdados da PNAD/IBGE.

\subsection{DINÂMICA DA DESIGUALDADE}

A distribuição acumulada do rendimento do trabalho oferece elementos adicionais para compreender a hierarquia e a heterogeneidade dos grupos ocupacionais (Figura 1). Em primeiro momento, visualiza-se a já mencionada hierarquia dos grupos ocupacionais, agora sob a forma de domínio das distribuições acumuladas. Por exemplo, o grupo de executivos, administradores e gerentes apresentava todos os quantis de renda superiores aos do grupo de profissionais, assim como o grupo de trabalhadores manuais não agrícolas em relação ao grupo de trabalhadores agrícolas. Isso significa que o primeiro cento mais pobre de executivos, administradores e gerentes possuía rendimento superior ao primeiro cento mais pobre de profissionais e assim sucessivamente até o cento mais rico.

A distribuição acumulada de renda também revela a má distribuição e a baixa magnitude dos rendimentos. Quanto à baixa magnitude, destacam-se a concentração de ocupados com baixos rendimentos e a baixa participação de ocupados com rendimentos relativamente elevados em praticamente todos os grupos ocupacionais. Por exemplo, em 2011, apenas os grupos de profissionais e técnicos, e executivos, administradores e gerentes apresentavam mais de $50 \%$ dos ocupados com rendimentos superiores a R \$1.000. Quanto à má distribuição, destaca-se a concentração de ocupados em uma pequena amplitude de baixos rendimentos e a dispersão dos rendimentos entre os relativamente ricos, o que caracteriza a elevada assimetria da distribuição de renda brasileira. Por exemplo, em 2011, aproximadamente 70\% dos trabalhadores manuais apresentavam rendimento igual ou inferior a $\mathrm{R} \$ 100$, e os $30 \%$ demais integrantes desse grupo apresentavam rendimentos que variavam entre $\mathrm{R} \$ 800$ e $\mathrm{R} \$ 40.000$ mensais. 
Figura 1 - Distribuição acumulada de renda dos ocupados remunerados segundo grupos ocupacionais (Brasil, 2002 e 2011)

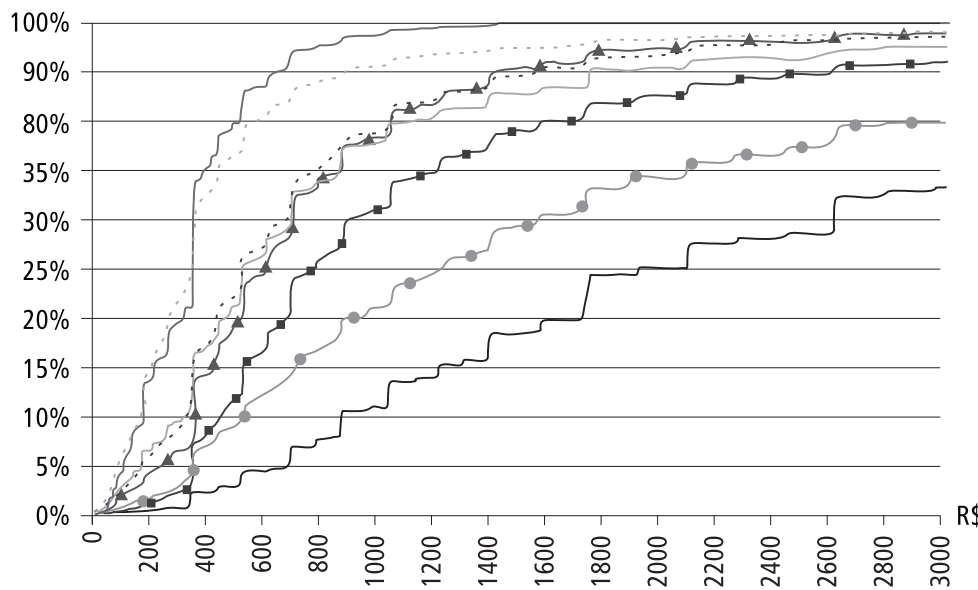

Exec., Adm. e Gerentes

Suporte Administrativo

Profissionais e Técnicos

-..... - Serviços
Empregados Domésticos Vendas

Trabalhadores Manuais

Trabalhadores Agrícolas

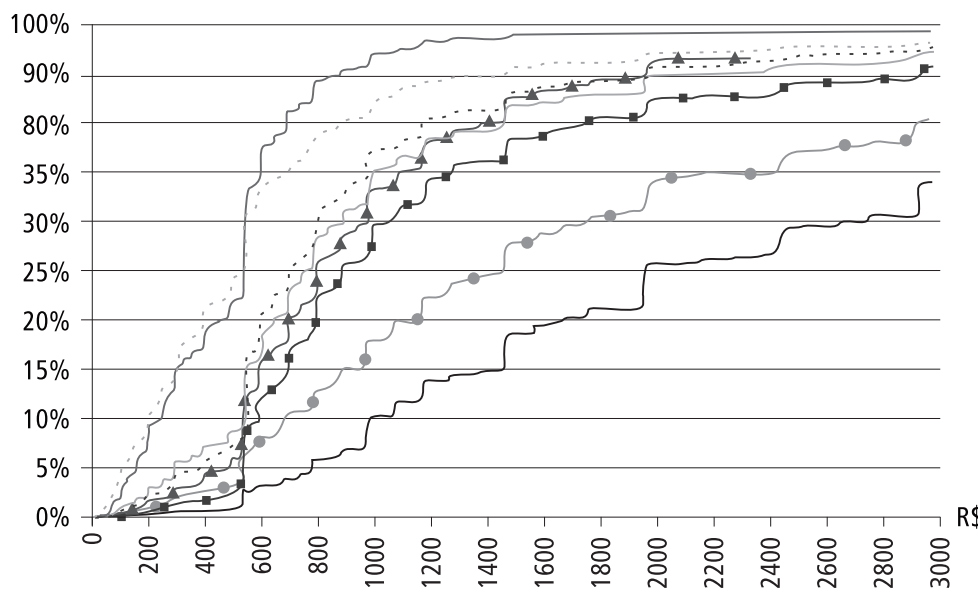

Exec., Adm. e Gerentes

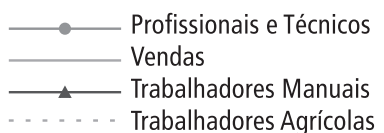

Nota: Valores em $1^{\circ}$ de outubro de 2011 (INPC corrigido para PNAD - IPEA).

Fonte: Elaboração própria com base em microdados da PNAD/IBGE. 
Comparando a distribuição de renda dos grupos ocupacionais, chama a atenção tanto a heterogeneidade entre integrantes de um mesmo grupo (heterogeneidade dentro) quanto entre integrantes de grupos distintos (heterogeneidade entre). Entre os grupos, por exemplo, têm-se alguns dos mais expressivos grupos da estrutura ocupacional (vendas, serviços e trabalhadores manuais) com medianas entre R\$ 700 e R $\$ 800$ em 2011, enquanto que os executivos, administradores e gerentes apresentavam uma mediana de aproximadamente $\mathrm{R} \$ 2.000$. Dentro dos grupos, destaca-se, por exemplo, a maior heterogeneidade dos rendimentos dos ocupados de vendas em relação à dos grupos de serviços e trabalhadores manuais. Até aproximadamente o oitavo décimo da população desses grupos (80\% mais pobres), o rendimento dos ocupados de vendas era muito próximo ao de ocupados de serviços e trabalhadores manuais. A partir do nono décimo (20\% mais ricos), o rendimento do grupo de vendas passa a ser superior ao dos trabalhadores manuais e de serviços. Em outras palavras, o maior rendimento médio dos ocupados de vendas deve-se, sobretudo, ao maior rendimento de poucos ocupados melhor remunerados neste grupo. A grande maioria dos ocupados desse grupo encontra-se, entretanto, em posição tão extrema quanto a dos trabalhadores manuais e de serviços. Comportamento análogo ocorre entre os grupos de trabalhadores domésticos e agrícolas. Os décimos mais pobres de trabalhadores agrícolas são tão pobres quanto os respectivos décimos de domésticos. Somente a partir do sétimo décimo, aproximadamente, os trabalhadores agrícolas passam a apresentar rendimentos superiores ao dos trabalhadores domésticos.

Uma síntese dos indicadores de desigualdade dentro e entre os grupos ocupacionais é apresentada na Tabela 5. Além do percentual dos rendimentos apropriado pelos $40 \%$ mais pobres e $10 \%$ mais ricos, são apresentados os indicadores $T$ de Theil para a desigualdade entre os grupos ocupacionais (TEG, equação 8), entre ocupações de um mesmo grupo ocupacional (TEO, equação 9) e entre integrantes de uma mesma ocupação (TDO, equação 10), para cada um dos grupos ocupacionais e para o conjunto de ocupados no Brasil.

Os indicadores revelam, por exemplo, que a desigualdade na distribuição dos rendimentos é elevada mesmo entre integrantes de um mesmo grupo ocupacional. Destaque pode ser dado à elevada desigualdade dos rendimentos dos ocupados agrícolas, o que estaria associada ao elevado número de trabalhadores conta própria em situação de extrema vulnerabilidade. Como parte predominante dos integrantes desse grupo apresenta baixíssima remuneração, aqueles poucos ocupados com rendimentos relativamente mais elevados acabam se apropriando de uma elevada parcela dos rendimentos totais. Neste grupo, os $10 \%$ mais ricos se apropriavam de $48 \%$ da renda total em 2002 e de $44 \%$ em 2011. 
Os grupos mais igualitários são aqueles não agrícolas menos qualificados, o que estaria associado à maior formalização em relação aos não agrícolas e a uma menor ocorrência de rendimentos elevados em relação aos grupos mais qualificados. Por exemplo, entre os empregados domésticos e os trabalhadores manuais, a massa de renda apropriada pelos $40 \%$ mais pobres era igual ou superior a $16 \%$ nos dois anos, e a massa apropriada pelos $10 \%$ mais ricos não era superior a 32\%. Entre os grupos relativamente mais qualificados, o rendimento médio é maior, mas a desigualdade também, o que estaria associado à diversidade de composições dessas categorias. $\mathrm{O}$ grupo de vendas, por exemplo, pode ser caracterizado tanto por um segmento associado às grandes e médias unidades varejistas, nas quais predominam relações formais de assalariamento e políticas sociais de bem-estar quanto a outro informal, associado à baixa profissionalização, o caráter irregular e transitório das ocupações e a inexistência de um sistema de proteção social.

Tabela 5 - Indicadores de desigualdade para o rendimento dos ocupados remunerados segundo grupos ocupacionais (Brasil, 2002 e 2011)

\begin{tabular}{|c|c|c|c|c|c|c|c|c|c|c|}
\hline \multirow[b]{2}{*}{ Grupo Ocupacional } & \multicolumn{5}{|c|}{2002} & \multicolumn{5}{|c|}{2011} \\
\hline & $\begin{array}{c}40 \% \\
\text { pobres }\end{array}$ & $\begin{array}{l}10 \% \\
\text { ricos }\end{array}$ & $T E G$ & $T E O$ & $T D O$ & $\begin{array}{c}40 \% \\
\text { pobres }\end{array}$ & $\begin{array}{l}10 \% \\
\text { ricos }\end{array}$ & $T E G$ & $T E O$ & $T D O$ \\
\hline $\begin{array}{l}\text { Executivos, } \\
\text { administradores e gerentes }\end{array}$ & 11,7 & 38,0 & 1,111 & 0,054 & 0,415 & 12,2 & 39,0 & 0,994 & 0,061 & 0,429 \\
\hline Profissionais e técnicos & 10,2 & 39,5 & 0,672 & 0,237 & 0,267 & 12,1 & 38,9 & 0,590 & 0,218 & 0,263 \\
\hline Suporte administrativo & 14,1 & 38,3 & 0,172 & 0,158 & 0,277 & 16,2 & 38,2 & 0,108 & 0,155 & 0,261 \\
\hline Vendas & 11,8 & 41,5 & $-0,137$ & 0,128 & 0,410 & 15,9 & 36,2 & $-0,154$ & 0,067 & 0,339 \\
\hline Serviços & 14,6 & 34,8 & $-0,315$ & 0,124 & 0,256 & 18,7 & 32,7 & $-0,279$ & 0,103 & 0,203 \\
\hline Trabalhadores manuais & 16,3 & 31,7 & $-0,295$ & 0,081 & 0,234 & 19,6 & 28,3 & $-0,221$ & 0,053 & 0,187 \\
\hline Empregos domésticos & 18,4 & 24,8 & $-1,083$ & 0,013 & 0,183 & 18,4 & 22,6 & $-0,939$ & 0,007 & 0,168 \\
\hline Trabalhadores agrícolas & 11,0 & 47,8 & $-0,660$ & 0,101 & 0,687 & 10,8 & 44,5 & $-0,539$ & 0,055 & 0,642 \\
\hline Total & 10,5 & 45,2 & 0,182 & 0,123 & 0,328 & 13,6 & 40,8 & 0,124 & 0,106 & 0,291 \\
\hline
\end{tabular}

Fonte: Elaboração própria com base em microdados da PNAD/IBGE.

Em 2011, 24\% da desigualdade total dos rendimentos medidos pelo $T$ de Theil deviam-se às diferenças entre os grupos ocupacionais (TEG igual a 0,124). Outros $20 \%$ deviam-se às diferenças entre ocupações de um mesmo grupo ocupacional (TEO igual a 0,106$)$. Em outras palavras, as diferenças entre os rendimentos médios dos oito grupos ocupacionais representariam quase um quarto da desigualdade total dos 151.699 rendimentos declarados na amostra de ocupados remunerados em 2011. Outros 20\% dessa desigualdade total seriam explicados pelas diferenças entre as 481 ocupações com pelo menos um rendimento declarado e os demais 55\% seriam devidos às diferenças 
dentro dessas ocupações, ou seja, entre integrantes de um mesmo grupo ocupacional e uma mesma ocupação.

O indicador TEG contém valores positivos para os grupos com rendimento médio superior a media nacional, ou seja, apenas para os três primeiros grupos da estrutura ocupacional. A magnitude absoluta do TEG, por sua vez, indica o grau de distanciamento da média de cada grupo ocupacional em relação à média nacional.

$O$ indicador TEO, que é uma medida da desigualdade dos rendimentos médios de ocupações de um mesmo agrupamento ocupacional, revela que os grupos de profissionais e técnicos, e trabalhadores do suporte administrativos apresentam as maiores diferenças em sua composição. Entre os profissionais e técnicos destaca-se, por exemplo, a diferença de rendimentos médios entre técnicos e auxiliares de enfermagem (média $52 \%$ inferior à do grupo em 2011) e advogados (média quase duas vezes superior à do grupo). Entre os trabalhadores do suporte administrativo destaca-se, por exemplo, a diferença de rendimentos médios entre recepcionistas (média 45\% inferior à do grupo) e contadores e auditores (média quase que três vezes superior à do grupo).

Houve uma expressiva redução da desigualdade entre 2002 e 2011 . O índice $T$ de Theil para o conjunto da população ocupada reduziu de 0,633 para 0,520 no período; queda de $18 \%$. A desigualdade entre os grupos reduziu-se mais aceleradamente devido, sobretudo, ao crescimento mais acelerado da renda média nos grupos da base da pirâmide social (Tabela 6). De maneira geral, a redução das diferenças entre os grupos (TEO) contribuiu com 5,8 pontos percentuais para a redução de 11,3 pontos percentuais no indicador $T$ (contribuição de 51,3\%). Adicionalmente, a redução das diferenças entre as ocupações de um mesmo grupo ocupacional contribuiu com outros 1,8 pontos percentuais (contribuição de 15,5\%).

A contribuição mais expressiva para a redução da desigualdade foi dada pelo grupo de executivos, administradores e gerentes. Embora este grupo represente uma pequena parcela dos ocupados (5,4\% em 2011), apropria-se de parcela expressiva dos rendimentos (14\% em 2011) e cumpre um papel importante na dinâmica no indicador $T$ de Theil. Entre 2002 e 2011, esse grupo contribuiu com 9 pontos percentuais para a redução do $T$, que representa $79,4 \%$ da variação total. As contribuições mais expressivas foram dadas pela redução da diferença entre seu rendimento médio e a média geral dos ocupados (contribuição de 7 pontos percentuais do efeito entre grupos para a redução da desigualdade, ou 61,9\%) e pela menor participação deste grupo com elevada desigualdade interna na estrutura ocupacional (contribuição de 1,8 pontos percentuais do efeito dentro das ocupações, ou 16\%). Outra contribuição relevante para a redução da desigualdade foi dada pelo grupo de vendas, sobretudo pela redução das diferenças dos rendimentos médios entre as ocupações desse grupo (contribuição de 5,2\% do efeito 
entre ocupações) e das diferenças dos rendimentos médios dos integrantes dessas ocupações (contribuição de 3,9\% do efeito dentro das ocupações). Os grupos de trabalhadores manuais e agrícolas contribuíram positivamente com a redução das diferenças de seus rendimentos em relação à média geral dos ocupados, mas negativamente pelo fato de terem observado simultaneamente uma redução das diferenças internas (seja entre as ocupações ou entre seus ocupados) e redução da participação na estrutura ocupacional.

\section{Tabela 6 - Decomposição do T de Theil para o rendimento dos ocupados remunerados} entre grupos, entre ocupações e dentro das ocupações (Brasil, 2002 e 2011)

\begin{tabular}{l|c|c|c|c|c|c|c|c}
\hline \multirow{2}{*}{ Grupo Ocupacional } & \multicolumn{3}{|c|}{ Variação Absoluta $(\Delta T)$} & \multicolumn{3}{c}{ Variação Relativa (\%) } \\
\cline { 2 - 10 } & $\begin{array}{c}\text { Efeito } \\
\text { entre } \\
\text { Grupos }\end{array}$ & $\begin{array}{c}\text { Efeito } \\
\text { entre } \\
\text { Ocup. }\end{array}$ & $\begin{array}{c}\text { Efeito } \\
\text { dentro } \\
\text { Ocup. }\end{array}$ & Total & $\begin{array}{c}\text { Efeito } \\
\text { entre } \\
\text { Grupos }\end{array}$ & $\begin{array}{c}\text { Efeito } \\
\text { entre } \\
\text { Ocup. }\end{array}$ & $\begin{array}{c}\text { Efeito } \\
\text { dentro } \\
\text { Ocup. }\end{array}$ & Total \\
\hline $\begin{array}{l}\text { Executivos, administradores } \\
\text { e gerentes }\end{array}$ & $-0,070$ & $-0,002$ & $-0,018$ & $-0,090$ & 61,9 & 1,4 & 16,1 & 79,4 \\
\hline Profissionais e técnicos & $-0,008$ & $-0,001$ & 0,003 & $-0,005$ & 6,9 & 0,6 & $-2,9$ & 4,6 \\
\hline Suporte administrativo & $-0,006$ & 0,000 & 0,000 & $-0,006$ & 5,3 & $-0,4$ & 0,3 & 5,2 \\
\hline Vendas & $-0,003$ & $-0,006$ & $-0,004$ & $-0,013$ & 2,8 & 5,2 & 3,9 & 11,9 \\
\hline Serviços & 0,001 & $-0,001$ & $-0,003$ & $-0,003$ & $-0,6$ & 0,7 & 2,4 & 2,5 \\
\hline Trabalhadores manuais & 0,013 & $-0,005$ & $-0,007$ & 0,000 & $-11,5$ & 4,8 & 6,5 & $-0,2$ \\
\hline Empregos domésticos & 0,004 & 0,000 & 0,000 & 0,003 & $-3,2$ & 0,2 & 0,3 & $-2,8$ \\
\hline Trabalhadores agrícolas & 0,012 & $-0,003$ & $-0,007$ & 0,001 & $-10,4$ & 3,0 & 6,6 & $-0,7$ \\
\hline Total & $-0,058$ & $-0,018$ & $-0,037$ & $-0,113$ & 51,3 & 15,5 & 33,1 & 100,0 \\
\hline
\end{tabular}

Fonte: Elaboração própria com base em microdados da PNAD/IBGE.

\section{CONSIDERAÇÕES FINAIS}

A economia e o mercado de trabalho brasileiro passaram por contextos bastante favoráveis nos anos 2000. Após crescer a taxas anuais médias inferiores a 2,5\% nos anos 1980 e 1990, a economia brasileira, beneficiada pela retomada da economia mundial, cresceu a uma taxa anual média de 3,9\% entre 2002 e 2011(IPEADATA, 2013). O impacto mais significativo no mercado de trabalho foi o crescimento no número e na qualidade dos empregos gerados. Entre 2002 e 2011, aumentou em 15,5 milhões o número de ocupados remunerados e a renda média do trabalho cresceu $22 \%$.

Fatores-chave para o crescimento da renda média do trabalho foram as mudanças observadas na estrutura ocupacional. Houve a redução, sobretudo, do número de ocupações menos qualificadas na agricultura e aumento, principalmente, do número de profissionais e trabalhadores de suporte administrativo, ocupações típicas de classe média (Quadros e Maia, 2010). A redução da parcela dos grupos ocupacionais e ocu- 
pações menos qualificadas e de baixo rendimento teve importante impacto na dinâmica do rendimento médio da população ocupada, sendo responsável por $12 \%$ de seu crescimento. Como a renda cresceu em praticamente todos os grupos ocupacionais, $88 \%$ da variação do rendimento médio acabou sendo dada pelo aumento da renda dos grupos ocupacionais.

Houve ainda importantes mudanças na distribuição de rendimentos dos grupos ocupacionais. Embora tenha crescido a participação de profissionais, técnicos e auxiliares administrativos, o rendimento médio dessas ocupações não acompanhou a variação da renda média das demais ocupações. Em outras palavras, as pessoas estariam se empregando em ocupações de rendimentos mais elevados, mas em situações relativas não tão favoráveis quanto em 2002. Uma possível justificativa para esse fenômeno seria o fato de a maior escolaridade da força de trabalho estar aumentando a oferta de mão de obra mais qualificada e, consequentemente, reduzindo os retornos pagos pela qualificação (ver, por exemplo, Ferreira et al., 2006). Outro fator relevante a ser considerado é a produtividade do trabalho. Maia e Menezes (2013) destacam que o crescimento no Brasil nos anos 2000 ocorreu com massiva incorporação de mão de obra e baixo crescimento da produtividade do trabalho. Como a produtividade é um determinante fundamental da renda do trabalho, haveria um limite natural para o crescimento das remunerações. Por sua vez, na base da pirâmide ocupacional os ganhos estariam associados tanto à política de contínua valorização do mínimo - base para pagamentos das ocupações menos qualificadas - quanto ao aumento da formalização e menor excedente de mão de obra. De acordo com Arbache (2011), o crescimento da população economicamente ativa brasileira desacelerou nos anos 2000, pressionando a oferta e a remuneração do trabalho.

A elevada participação de ocupações da base da estrutura ocupacional e as extremas diferenças de remuneração em relação à pequena parcela de ocupações mais qualificadas ajudam a explicar, em grande medida, o elevado grau de desigualdade no mercado de trabalho. Aproximadamente um quarto da desigualdade total dos rendimentos do mercado de trabalho deve-se às diferenças de remuneração entre os oito grupos ocupacionais identificados nas análises. Outros $20 \%$ seriam explicados pelas diferenças entre os rendimentos médios das ocupações que compõem esses grupos ocupacionais.

O universo das ocupações agrícolas é o que apresenta a maior concentração na distribuição de rendimentos, que estaria associada ao elevado número de trabalhadores conta-própria em condições vulneráveis de remuneração. Entre os grupos ocupacionais não agrícolas, aqueles mais qualificados tendem a ser os mais desiguais, como resultado da extrema complexidade de situações a que os ocupados desses grupos estariam submetidos. 
A desigualdade caiu entre e dentro de praticamente todos os grupos ocupacionais e, no conjunto total da população ocupada, houve uma sensível melhora nos extremos graus de desigualdade do mercado de trabalho brasileiro. Fator fundamental para essa redução foi a redução das diferenças entre as ocupações. Mais da metade da queda da desigualdade entre 2002 e 2011 se deveu à redução das diferenças entre os grupos ocupacionais e outros $15 \%$ se deveram à redução das diferenças entre as ocupações que compõem esses grupos.

De maneira geral, pode-se afirmar que a estrutura ocupacional é um importante elemento para análise da desigualdade socioeconômica. Além de definir em grande medida - as oportunidades presentes de geração de renda na economia, as ocupações estão associadas às perspectivas futuras de desenvolvimento socioeconômico das pessoas. Embora a composição da estrutura ocupacional brasileira tenha melhorado sensivelmente nos anos 2000, destaca-se ainda a necessidade de profundas melhorias na qualidade e quantidade das ocupações mais qualificadas, que seriam fundamentais para aumentar a renda e reduzir a extrema desigualdade da distribuição de renda da economia brasileira.

\section{REFERÊNCIAS}

ARBACHE, J. Transformação demográfica e competitividade internacional da economia brasileira. Revista do BNDES, n. 36, 2011.

BALTAR, P. “Crise contemporânea e mercado de trabalho no Brasil”. In: OLIVEIRA, M. A. (Ed.) Economia e Trabalho. Campinas: Universidade Estadual de Campinas, 1998, p. 147-161.

BLAU, P. M.; DUNCAN, O. D. The American occupational structure. New York: John Wiley \& Sons, 1967.

BUAINAIN, A. M.; DEDECCA, C. S. Emprego e trabalho na agricultura brasileira. Brasília: IICA, 2008.

COMISIÓN ECONÓMICA PARA AMÉRICA LATINA Y EL CARIBE (CEPAL). Reflexiones sobre el crecimiento económico de América Latina y el Caribe. Santiago: Estudio económico de América Latina y el Caribe 2006-2007, LC/G.2338-P/E, 2007.

CORSEUIL, C. H. L.; FOGUEL, M. Uma sugestão de deflatores para rendas obtidas a partir de algumas pesquisas domiciliares do IBGE. Texto para Discussão, IPEA, Rio de Janeiro, $\mathrm{n}$. $897,2002$.

CORSEUIL, C. H. L.; RAMOS, L.; FURTADO, L.; AGUAS, M. "Mercado de trabalho". In: ABRAHÃO, J.; VAZ, F. M. (Eds.) Situação social no Brasil: monitoramento das condições de vida 1. Brasília: IPEA, 2011, p. 284.

FERREIRA, F. H. G.; LEITE, P. G.; LITCHFIELD, J. A.; ULYSSEA, G. Ascensão e queda da desigualdade de renda no Brasil. Econômica, v. 8, n. 1, p. 149-171, 2006. 
FISHLOW, A. Brazilian size distribution of income. The American Economic Review, v. 62, n. 1/2, p. 391-402, 1972.

FURTADO, C. Formação econômica do Brasil. 21 ed. São Paulo: Editora Nacional, 1986.

GASQUES, J. C.; VIERIA FILHO, J. E. R.; NAVARRO, Z. S. A agricultura brasileira: deságios e perspectivas. Brasília: IPEA, 2010.

HOFFMANN, R. Distribuição de renda: medidas de desigualdade e pobreza. São Paulo: Editora da USP, 1998.

HOFFMANN, R.; DUARTE, J. C. A distribuição de renda no Brasil. Revista de Administração de Empresas, v. 12, n.2, p. 46-66, 1972.

HOFFMANN, R.; NEY, M. G. A recente queda da desigualdade de renda no Brasil: análise de dados da PNAD, do Censo Demográfico e das Contas Nacionais. Econômica, v. 10, n. 1, p. 7-39, 2008.

HULL, K. "Understanding the relationship between economic growth, employment and poverty reduction". In: ORGANIZATION FOR ECONOMIC COOPERATION AND DEVELOPMENT (OECD) Promoting pro-poor growth: employment. OECD, 2009, p. 69-94.

INSTITUTO DE PESQUISA ECONÔMICA APLICADA (IPEA). IPEADATA. [on line] Disponível em: <http://www.ipeadata.gov.br>. Acesso em: 29 jun. 2013

LANGONI, C. G. Distribuição da renda e desenvolvimento econômico do Brasil. Rio de Janeiro: Expressão e Cultura, 1973.

MAIA, A. G. Estrutura de classes e desigualdade no Brasil. Campinas: Ltr, 2009.

MAIA, A. G.; QUADROS, W. Dinâmica das ocupações no Brasil em duas décadas de baixo crescimento econômico. Revista da ABET, v. 9, n. 2, p. 143-161, 2010.

MAIA, A. G.; MENEZES, E. The relation between economic growth, labor and productivity in Brazil and the United States: a comparative analysis. Revista de Economia Política, 2013. No prelo.

MENEZES-FILHO, N. A. A evolução da educação no Brasil e seu impacto no mercado de trabalho. Instituto Futuro Brasil, 2001

MILLS, W. A nova classe média. 3 ed. Rio de Janeiro: Zahar Editores, 1979.

OLIVEIRA, C. A. B.; HENRIQUE, W. Determinantes da pobreza no Brasil: um roteiro de estudo. São Paulo em Perspectiva, v. 4, n. 2, p. 25-28, 1990.

ORGANIZAÇÃO INTERNACIONAL DO TRABALHO (OIT). World Employment Report 20042005: Employment, productivity and poverty reduction. Genebra: Organização Internacional do Trabalho, 2005.

PORTES, A.; HOFFMAN, K. Latin American class structures: their composition and change during the neoliberal era. Latin American Research Review, v. 38, n. 1, p. 41-82, 2003.

PREBISCH, R. Hacia una teoria de la transformación. Revista CEPAL, n. 96, p. 27-71, 2008.

QUADROS, W.; MAIA, A. G. Estrutura sócio-ocupacional no Brasil. Revista de Economia Contemporânea, v. 14, n. 3, p. 443-468, 2010. 
ROSE, D.; HARRISON, E. The European socio-economic classification: a new social class schema for comparative European research. European Societies, v. 9, n. 3, p. 459-490, 2007.

SABOIA, J. Elasticidades dos rendimentos do trabalho em relação ao salário mínimo: a experiência de um período recente de crescimento do salário mínimo. Economia e Sociedade, v. 19, n. 2, p. 359-380, 2010.

\section{Apêndice A - Distribuição dos ocupados remunerados segundo grupos ocupacionais} e grau de escolaridade (Brasil, 2002 e 2011)

\begin{tabular}{l|c|c|c|c|c|c|c|c}
\hline \multirow{2}{*}{\multicolumn{1}{c|}{ Grupo Ocupacional }} & \multicolumn{7}{c|}{$\mathbf{2 0 0 2}$} & \multicolumn{4}{c}{$\mathbf{2 0 1 1}$} \\
\cline { 2 - 10 } & $\begin{array}{c}\mathbf{1}^{\mathbf{0}} \\
\text { Grau }\end{array}$ & $\begin{array}{c}\mathbf{2}^{\mathbf{0}} \\
\text { Grau }\end{array}$ & $\begin{array}{c}\mathbf{3}^{\mathbf{0}} \\
\text { Grau }\end{array}$ & Total & $\begin{array}{c}\mathbf{1}^{\mathbf{0}} \\
\text { Grau }\end{array}$ & $\begin{array}{c}\mathbf{2}^{\mathbf{o}} \\
\text { Grau }\end{array}$ & $\begin{array}{c}\mathbf{3}^{\mathbf{0}} \\
\text { Grau }\end{array}$ & Total \\
\hline $\begin{array}{l}\text { Executivos, administradores e } \\
\text { gerentes }\end{array}$ & 26,6 & 35,4 & 38,1 & 100,0 & 18,1 & 35,3 & 46,6 & 100,0 \\
\hline Profissionais e técnicos & 12,7 & 30,6 & 56,6 & 100,0 & 7,7 & 25,7 & 66,6 & 100,0 \\
\hline Suporte administrativo & 14,9 & 53,9 & 31,2 & 100,0 & 9,0 & 48,3 & 42,8 & 100,0 \\
\hline Vendas & 48,2 & 41,7 & 10,1 & 100,0 & 30,8 & 52,6 & 16,6 & 100,0 \\
\hline Serviços & 61,7 & 33,2 & 5,2 & 100,0 & 41,7 & 48,5 & 9,8 & 100,0 \\
\hline Trabalhadores manuais & 74,3 & 23,6 & 2,2 & 100,0 & 56,8 & 38,5 & 4,7 & 100,0 \\
\hline Empregos domésticos & 83,3 & 16,2 & 0,5 & 100,0 & 69,8 & 28,1 & 2,1 & 100,0 \\
\hline Trabalhadores agrícolas & 93,9 & 5,1 & 1,0 & 100,0 & 84,6 & 13,5 & 1,9 & 100,0 \\
\hline Total & 58,4 & 27,9 & 13,6 & 100,0 & 42,2 & 37,6 & 20,2 & 100,0 \\
\hline
\end{tabular}

Nota: Dados em \%.

Fonte: Elaboração própria com base em microdados da PNAD/IBGE. 